\title{
aß-Dehydrocurvularin isolated from the fungus Aspergillus welwitschiae effectively inhibited the behaviour and development of the root-knot nematode Meloidogyne graminicola in rice roots
}

\section{Chao xiang}

Institute of plant protection, Chinese Academy of Agricultural Sciences

Ying Liu

Institute of Plant Protection, Chinese Academy of Agricultural Sciences

Shi-Ming Liu

Institute of Plant Protection, Chinese Academy of Agricultural Sciences Institute of Bast Fiber Crops

Ya-Fei Huang

College of Chemical Engeneering, Beijing University of Chemical Technology

Ling-An Kong

Chinese Academy of Agricultural Sciences Institute of Plant Protection

Huan Peng

Institute of Plant protection, Chinese Academy of Agricultural Sciences

Mao-Yan Liu

Institute of Plant Protection, Chinese Academy of Agricultural Sciences

Jing Liu

Hunan Agriclture University

De-Liang Peng

Institute of Plant Protection, Chinese Academy of Agricultural Sciences

Wen-Kun Huang ( $\nabla$ wkhuang2002@163.com )

Chinese Academy of Agricultural Sciences Institute of Plant Protection https://orcid.org/0000-00021106-9308

\section{Research article}

Keywords: Meloidogyne graminicola, aß-dehydrocurvularin, nematicidal activity, attractiveness, development, behaviour

Posted Date: December 18th, 2019

DOl: https://doi.org/10.21203/rs.2.19185/v1 
License: (c) (1) This work is licensed under a Creative Commons Attribution 4.0 International License. Read Full License

Version of Record: A version of this preprint was published at BMC Microbiology on March 4th, 2020. See the published version at https://doi.org/10.1186/s12866-020-01738-2. 


\section{Abstract}

Background: The root-knot nematode Meloidogyne graminicola has become a serious threat to rice production as a result of the cultivation changes from transplanting to direct seeding. The nematicidal metabolites of Aspergillus welwitschiae have been investigated in vitro, and the disease control efficacy of the active compound has been evaluated under greenhouse and field conditions.

Results: The active compound $\alpha \beta$-dehydrocurvularin ( $\mathrm{a} \beta-\mathrm{DC}$ ), isolated by nematicidal assay-directed fractionation, showed significant nematicidal activity against $M$. graminicola, with an median lethal concentration $\left(\mathrm{LC}_{50}\right.$ ) value of $122.2 \mu \mathrm{g} \mathrm{mL}^{-1}$. a $\mathrm{\beta}-\mathrm{DC}$ effectively decreased the attraction of rice roots to nematodes and the infection of nematodes and also suppressed the development of nematodes under greenhouse conditions. Moreover, $a \beta-D C$ efficiently reduced the root gall index under field conditions.

Conclusion: To our knowledge, this is the first report to describe the nematicidal activity of a $\beta-D C$ against M. graminicola. The results obtained under greenhouse and field conditions provide a basis for developing commercial formulations from a $\beta$-DC to control M. graminicola in the future.

\section{Background}

The root-knot nematode (RKN) Meloidogyne graminicola is considered one of the most devastating pests on rice, especially in southern Africa, America and Southeast Asia $[12,19,24]$. This nematode penetrates rice roots and induces the formation of giant cells as the nutrition resource throughout its life cycle, with a typical symptom of hook-like galls on the roots [20]. M. graminicola impedes the uptake of water and nutrients due to the formation of giant cells in rice roots and causes significant yield losses in most riceproducing areas. The annual yield loss caused by $\mathrm{M}$. graminicola is estimated at $16 \% \varangle 87 \%[8,29,32,38]$. M. graminicola is difficult to control because it has a short generation and high reproduction rate [11].

In the past few decades, chemical control (e.g., organophosphates, carbamates and chlorpyriphos) was the primary means for managing this nematode [15]. Soil application of phorate and fosthiazate before seeding and soaking rice seedlings in carbosulfan and chlorpyriphos solutions both significantly reduced root galling on rice plants [33]. However, due to the side effects of these chemicals on the environment and humans, many chemical nematicides have been withdrawn or restricted $[3,6]$. MeBr was completely phased out in 2015 because of its negative effect on stratospheric ozone [1]. Sulfuryl fluoride might play an important role in global warming because of its chemical stability [39]. In addition, policies have been designed to support environmentally friendly farming practices in many countries, and eco-friendly alternatives are increasingly demanded. Thus, much research has aimed to identify nematicidal metabolites from antagonistic microorganisms to control RKNs [10, 16, 35]. However, few commercial products have been developed and applied in agriculture. Therefore, the identification of antagonists is necessary for the control of RKN and its commercialization.

Biological control of endophytic fungi has been demonstrated to be effective in reducing the penetration and reproduction of plant-parasitic nematodes $[21,22,25,40]$. Le et al. [21, 22] reported that the root- 
galling severity of $\mathrm{M}$. graminicola was reduced by $38 \%$ with treatment of Trichoderma spp. and that $\mathrm{M}$. graminicola penetration was significantly reduced by $55 \%$ by endophytic Fusarium moniliforme colonization. Aspergillus species are very common in soils, and many scientific studies have indicated that metabolites isolated from Aspergillus spp. have high potential for plant-parasitic nematode management [2]. Li et al [23]. found that A. niger could reduce $M$. incognita populations and promote tomato growth. According to Jin et al. [13], metabolites of A. niger caused $90 \%$ mortality of second-stage juveniles and remarkably reduced the penetration of Heterodera glycines in soybean roots. a $\beta-$ Dehydrocurvularin ( $\mathrm{a} \beta-\mathrm{DC}$ ) was first identified as a metabolite of $A$. aureofulgens by Caputo and Viola [4]. Previous studies showed that $\alpha \beta-D C$ isolated from different microorganisms had various antimicrobial activities and nematicidal activities $[4,18]$. a $\beta$-DC also showed weak activity against gram-positive and gram-negative bacteria [4], while $\beta \gamma$-DC could cause $35 \%$ mortality in Pratylenchus penetrans at a concentration of $300 \mathrm{~g} \mathrm{~mL}^{-1}$ [18]. However, the nematicidal activity and the action mode of aß-DC against RKN M. graminicola have not yet been determined.

Therefore, further insights into the nematicidal activity of aß-DC against $M$. graminicola were obtained in this study, which aimed to identify a potential alternative to control M. graminicola. To provide further evidence of the effects of $a \beta-D C$ on M. graminicola and to elucidate the mechanism of action, the effects of $\alpha \beta-D C$ on nematode survival, giant cell development, locomotion behaviour and reproductive activity were evaluated at room temperature, and the infectivity of nematodes to rice plants was also evaluated under field conditions in this study.

\section{Results}

Identification of aß-Dehydrocurvularin from A. welwitschiae

In total, $15.2 \mathrm{~g}$ crude filtrates were extracted by $\mathrm{CHCl}_{3} / \mathrm{MeOH}$ eluent from fermentations of $\mathrm{A}$. welwitschiae and were purified by column chromatography on silica gel. Then, $285 \mathrm{mg}$ of the active fraction was repeatedly crystallized from $\mathrm{Me}_{2} \mathrm{CO} /$ EtoAc and produced as a white powder. By comparing the physiochemical properties with those reported previously, the purified nematicidal compounds from $A$. welwitschiae were identified as aß-dehydrocurvularin ( $\alpha \beta-D C)$, with a chemical structure as shown in Fig. 1.

Nematicidal effects of $a \beta-D C$ on $M$. graminicola juveniles

The mortality curves of M. graminicola juveniles exposed to fosthiazate, fluopyram or a $\beta-D C$ are shown in Fig. 2. Fosthiazate remarkably displayed the highest nematicidal activity among these three compounds. The activity of $a \beta-D C$ was significantly lower than that of fosthiazate at concentrations above $120 \mathrm{mg} \mathrm{ml}^{-}$ ${ }^{1}$, while no difference could be observed between them at low concentrations. No significant difference was observed between a $\beta-D C$ and fluopyram, except at the concentration of $30 \mu \mathrm{g} \mathrm{ml}^{-1}$. Based on the nematode mortality curves, the $\mathrm{LC}_{50}$ values of $\mathrm{a} \beta-\mathrm{DC}$, fosthiazate, and fluopyram for M. graminicola J2s 
were $122.2,89.1$, and $139.6 \mu \mathrm{g} \mathrm{mL}^{-1}$, respectively, which means that the nematicidal activity of aß-DC was similar to that of FLU but was significantly lower than that of fosthiazate.

Effect of $a \beta-D C$ on the attractiveness of rice roots to M. graminicola and giant cell development

To determine whether $\mathrm{a} \beta-D C$ has a direct effect on the attractiveness of roots to $M$. graminicola, we counted the numbers of nematodes attracted to within $5 \mathrm{~mm}$ around the roots treated with aß-DC or DMSO solution. At $6 \mathrm{hpi}$, the numbers of nematodes attracted to the aß-DC-treated root tips $(14.3 \pm 2.9)$ were significantly lower than those attracted to the control roots $(22.3 \pm 2.0)$ (Fig. 3a and b). This result indicates that the tested chemicals prevented the attraction of rice roots to M. graminicola.

A microscopic investigation of giant cells revealed a significant difference in the morphological characteristics of feeding sites in the $\mathrm{a} \beta$-DC-treated roots versus the non-treated roots. The volume of giant cell transections in the $\alpha \beta$-DC-treated roots $\left(720.3 \pm 176.2 \mu \mathrm{m}^{2}\right)$ was significantly lower than that in the DMSO-treated roots $\left(2636.1 \pm 250.2 \mu \mathrm{m}^{2}\right)$ (Fig. $4 \mathrm{a}$ and b). However, no significant differences were observed in the numbers of giant cells per feeding site between the a $\beta$-DC-treatment $(6.2 \pm 1.3)$ and nontreated control (6.6 \pm 1.1$)$ (Fig. 4c). These data demonstrate that the $\alpha \beta-D C$ treatment had a visibly negative effect on giant cell development, thus decreasing the supply of nutrients to the nematodes.

\section{Effect of aß-DC on the development and infectivity of nematodes}

To evaluate the effect of $\mathrm{a} \beta-\mathrm{DC}$ on $\mathrm{M}$. graminicola development, nematodes in rice plants drenched with $a \beta-D C$ or DMSO solution were counted in a greenhouse experiment. Drenching with $a \beta-D C$ significantly decreased nematode penetration compared with control plants. At $14 \mathrm{dpi}$, the observation of nematodes in fuchsin-stained roots showed that the nematode numbers in the FOS treatment $(36.6 \pm 4.9 \%)$ were significantly lower than those in the a $\beta$-DC treatment (55.4 $\pm 7.7 \%)$ and FLU treatment $(52.7 \pm 7.0 \%)$ (Fig. 5a), and all the treatments resulted in a significant reduction in total nematode numbers compared to the control roots $(113.4 \pm 12.5)$. In addition, the development of nematodes in $\alpha \beta$-DC-treated plants was slightly delayed compared with the control plants (Fig. $5 b$ and c). The percentage of J3/J4s in a 3 -DCtreated plants $(22.2 \pm 4.2 \%)$ was significantly higher than that in control plants $(4.6 \pm 0.9 \%)$, whereas a lower ratio of females was observed in a $\beta$-DC-treated roots $(77.8 \pm 6.7 \%)$ than in control roots $(95.4 \pm$ 4.3\%). However, no significant differences in the percentage of $\mathrm{J} 3 / \mathrm{J} 4 \mathrm{~s}$ or females were observed among the control plants, FOS-treated plants and FLU-treated plants. These data suggest that drenching with a $\beta$ DC decreased nematode infection and delayed nematode development inside the rice roots.

Root galls are typically a direct reflection of nematode infection levels and always correlate with the susceptibility of rice varieties to nematodes [42]. To evaluate the effect of $a \beta-D C$ on the infection of nematodes under field conditions, a field experiment was conducted on a commercial rice base that had been naturally infected with $\mathrm{M}$. graminicola for more than 10 years. Field experiments also demonstrated the negative effect of $a \beta-D C$ on the infectivity of M. graminicola. At $50 \mathrm{~d}$ after direct seeding, the root gall 
index of rice roots was significantly decreased in all the treatments (Fig. 6a). The lowest root gall index was observed in the FOS treatment $(21.5 \pm 4.1 \%)$, which significantly differed from the FLU treatment $(31.7 \pm 6.5 \%)$ and the $a \beta$-DC treatment $(38.4 \pm 3.6 \%)$. No significant differences in the root gall index were observed between $a \beta-D C$ and FLU treatments. The highest root gall index was observed in the DMSO control $(65.8 \pm 8.4)$. Among the three chemical treatments, the FOS treatment exhibited the highest control efficacy $(67.3 \pm 8.6 \%)$ in reducing the root gall index, followed by the FLU treatment $(51.8 \pm 9.5 \%)$, while the $a \beta-D C$ treatment showed the lowest control efficacy $(41.6 \pm 7.4)$ (Fig. 6b). These data suggest that drenching with $a \beta-D C$ markedly decreased the infection of M. graminicola in rice fields.

\section{Discussion}

The root-knot nematode M. graminicola has been considered to be a serious threat to rice production with the transformation of cultivation modes from transplanting to direct seeding. Consequently, new biologically active metabolites are required to qualify the increasing demand for controlling $M$. graminicola. In the present study, we demonstrated that $\alpha \beta-D C$ extracted from A. welwitschiae was toxic to M. graminicola juveniles. The application of $\alpha \beta-D C$ decreased the attractiveness of rice roots to nematodes, reduced nematode infection and retarded the development of nematodes in rice roots. These results indicate that the natural product $\mathrm{a} \beta-\mathrm{DC}$ isolated from $\mathrm{A}$. welwitschiae may be a highly promising source of chemicals to manage M. graminicola. To our knowledge, this is the first report to detail the suppression effect of aß-DC on M. graminicola.

After measurement of the toxic effect of this compound on nematodes, further research was conducted to determine the action mode of $\mathrm{a} \beta-\mathrm{DC}$, with analyses of nematode infectivity, development and attraction behaviour after application of $\alpha \beta-D C$. To date, only a few host- or non-host-specific compounds are known to mediate the attractiveness of crops to nematodes [7, 22, 28]. Diez and Dusenbery [7] observed that carbon dioxide or amino acids helped RKN M. incognita to trace tomato roots. Based on the present research, it is evident that the application of a $\mathrm{\beta}-\mathrm{DC}$ significantly decreased the attractiveness of rice roots to $\mathrm{M}$. graminicola, thus hindered nematode invasion and subsequent infection. Le et al. [22] also observed that the root exudates from F. moniliforme Fe14-treated plants decreased the attractiveness of M. graminicola to host roots. However, root exudates from Pseudomonas fluorescenstreated plants had no effects on the attractiveness of cyst nematode $\mathrm{H}$. schachtii in sugar beet [28]. Thereafter, the principle method by which nematodes locate different host roots remains to be discovered.

As previously reported, dehydrocurvularin is a unique compound produced by Aspergillus spp. and has various antimicrobial activities and nematicidal activities $[4,18,34]$. Kusano et al. [18] reported that $\beta Y-D C$ caused a mortality of $35 \%$ in Pratylenchus spp. at a concentration of $300 \mu \mathrm{g} \mathrm{mL}^{-1}$. In the present study, our experimental results indicated that $\mathrm{a} \beta-D C$ had significant nematicidal activity against $M$. graminicola in an in vitro test, with an $\mathrm{LC}_{50}$ of approximately $122.2 \mu \mathrm{g} \mathrm{mL}^{-1}$, which is similar to the effect of the chemical nematicide fluopyrum. However, the nematicidal activity of a $\beta$-DC against $J 2 s$ of $M$. graminicola was significantly higher than that of $\beta \gamma$-DC against $P$. penetrans. These results strongly 
suggested that the nematicidal activity of $\alpha \beta-D C$ was closely related to its strong arrest of infection. Therefore, $a \beta-D C$ can be used as a promising biopesticide for the control of RKN.

The slowing reproduction of $\mathrm{M}$. graminicola in the greenhouse experiment also indicated that a $\mathrm{\beta}-\mathrm{DC}$ retarded nematode development in rice roots. In previous investigations, some chemicals have been demonstrated to arrest larval development [30]. Exogenous chemicals (e.g., benomyl, nocodazole) or starvation affected cellular processes in the embryo, larvae or adult germline of Caenorhabditis elegans. Furthermore, Kearn et al. [14] found that fluensulfone suppressed the development of C. elegans by interfering with larval moulting. However, the mechanism underlying the arrested development caused by $a \beta-D C$ remains unclear. In the present research, the volume of giant cell transections in the a $\beta$-DC-treated roots was significantly lower than that in the non-treated roots. Based on the morphological changes of giant cells, we speculated that drenching with a $\beta-D C$ retarded the development of giant cells, which might decrease the food supply of nematodes and thus suppress the growth, development and cell cycle progression of M. graminicola. However, the exact action mechanism of a $\beta$-DC against nematode development remains to be verified in the future.

With the banned use of many chemical nematicides, searches for biological control agents and more environmentally benign control methods are ongoing [36, 37]. In the present field experiment, the drenching of aß-DC significantly decreased the root gall index of rice roots, with the control efficacy as high as $40 \%$ in controlling $M$. graminicola, which was similar to the effect of chemical fluopyrum. This suggests that $\mathrm{a} \beta-\mathrm{DC}$ remarkably decreases the infection of $\mathrm{M}$. graminicola in rice fields.

Based on the results of this study, $a \beta-D C$ exhibited significant nematicidal activity against $M$. graminicola and provided substantial control of RKN in the field, which implies that a $\beta-D C$ will be a promising control agent for M. graminicola. The mode of its action was also elucidated with analyses of nematode infectivity, development and attraction behaviour. However, further research is required to determine its effect on crops and the environment and to then develop commercial formulations with high efficacy and low cost in farm practices.

\section{Conclusion}

To our knowledge, this is the first report to describe the nematicidal activity of a $\beta-D C$ against $M$. graminicola. aß-DC effectively decreased the infection of nematodes, and suppressed the behaviour and development of nematodes in rice roots, which provide a basis for developing commercial formulations from $\alpha \beta-D C$ to control M. graminicola in the future.

\section{Methods}

Identification of nematicidal compounds from A. welwitschiae

The A. welwitschiae strain AW2017 was cultured on potato dextrose broth (PDB) medium (50 L) at $25^{\circ} \mathrm{C}$ for $5 \mathrm{~d}$ [24]. The nematicidal compounds were isolated from AW2017 metabolites as described by 
Kusano et al. [18] with minor modifications. Briefly, the culture filtrate was extracted with $\mathrm{CHCl}_{3} / \mathrm{MeOH}$ eluent and evaporated under reduced pressure. The crude material was purified by column chromatography on silica gel, and the active fractions were repeatedly crystallized from $\mathrm{Me}_{2} \mathrm{CO} / \mathrm{EtoAc}$ to produce nematicidal compounds, which were used to analyse its nematicidal activities simultaneously. Final products were identified by comparing the physiochemical properties with those reported previously $[4,18,34]$. All the chemicals used in the present research were purchased from Sigma-Aldrich (China).

\section{Rice culture and propagation of the nematode}

Rice seeds (Oryza sativa cv. Nipponbare) were originally obtained from the US Department of Agriculture (GSOR-100) and multiplicated in Hunan Province, China. Seeds were soaked in $5.25 \%$ sodium

hypochlorite for $5 \mathrm{~min}$ and germinated at room temperature $\left(25 \pm 4^{\circ} \mathrm{C}\right)$ for $4 \mathrm{~d}$. One geminated seed was sown in a polyvinylchloride (PVC) tube containing synthetic absorbent polymer (SAP) [43]. Rice seedlings grew in a greenhouse and were irrigated with $20 \mathrm{ml}$ of Hoagland's solution twice per week at $28 \pm 2{ }^{\circ} \mathrm{C}$ with $70-75 \%$ relative humidity.

The M. graminicola population was propagated on the susceptible rice variety Nipponbare at $28 \pm 2{ }^{\circ} \mathrm{C}$. Nematode eggs were separated from the root galls and hatched in a $75-\mu \mathrm{m}$ sieve at room temperature for 3-5 d. Hatched second-stage juvenile (J2) suspensions were filtered through a $25-\mu \mathrm{m}$ sieve and resuspended in distilled water at approximately 200 nematodes $\mathrm{mL}^{-1}$ for the subsequent experiments $[27,43]$.

Larvicidal activity of $a \beta-D C$ against $M$. graminicola

To test the larvicidal activity of a $\beta-D C$, approximately 200 hatched $\mathrm{J} 2$ individuals were added to each well of 24-well plates containing $1 \mathrm{ml}$ of $\alpha \beta-D C$ solution at $480,240,120,60$, and $30 \mu \mathrm{g} \mathrm{mL}^{-1}$. Forty-eight percent fosthiazate emulsifiable concentrate (FOS, EC) and $41.7 \%$ fluopyram suspension concentrate (FLU, SC) were also diluted to $480,240,120,60,30 \mu \mathrm{gL}^{-1}$ as described above and used as positive controls. A treatment with only I $\mathrm{ml}$ of a $1 \%$ dimethyl sulfoxide (DMSO) water solution was included as the negative control. Four replicates were set for each treatment. The plates were kept at $25^{\circ} \mathrm{C}$ for $48 \mathrm{~h}$. Nematodes were considered dead if their bodies were motionless and straightened after stimulation with $1 \mathrm{M} \mathrm{NaOH}$ [5]. The dead and alive juveniles were counted under a stereomicroscope, and the corrected mortality values of juveniles were calculated as described in Liu et al [24]. The median lethal concentration ( $\left(\mathrm{LC}_{50}\right)$ of $\mathrm{a} \beta-\mathrm{DC}$ and other chemicals against nematodes were analysed with SAS software(SAS Institute, Cary, NC). Three trials with four replicates were performed for this experiment.

Effect of $\alpha \beta-D C$ on the attractiveness of rice roots to M. graminicola

As described in Wang et al. [41] $23 \mathrm{~g}$ pluronic F-127 powder was fully dissolved in $100 \mathrm{~mL}$ of sterile water at $4{ }^{\circ} \mathrm{C}$ while stirring for $24 \mathrm{~h}$. Then, an attraction bioassay was performed at room temperature. Rice 
roots of 2-week-old plants were drenched with $20 \mathrm{~mL} \mathrm{a \beta -DC}\left(30 \mu \mathrm{g} \mathrm{mL}^{-1}\right)$ solution or $1 \%$ DMSO water solution. One day later, a 1-cm-long root tip was cut and placed into a six-well culture plate containing $1 \mathrm{~mL}$ pluronic F-127 gel and approximately 100 hatched J2s. Nematodes attracted to $5 \mathrm{~mm}$ around the root tip were counted under a Leica stereomicroscope and were photographed with a DFC400 camera at $6 \mathrm{~h}$ post inoculation (hpi). The entire experiment was performed thrice, with four replicates.

\section{Morphological observation of nematode giant cells}

After J2s enter the vascular cylinder, they inject pharyngeal secretions to induce permanent feeding sites known as giant cells, which are used as food resources throughout their life cycle [9]. To observe the morphological changes of nematode giant cells, each rice plant was drenched with $20 \mathrm{ml} \mathrm{a \beta -DC} \mathrm{(30 \mu g}$ $\left.\mathrm{mL}^{-1}\right)$. Plants drenched with DMSO solution were used as the control. One day later, each plant was inoculated with $100 \mathrm{~J} 2 \mathrm{~s}$. At $7 \mathrm{~d}$ post inoculation (dpi), 10 root galls from six plants were fixed in $1 \mathrm{x}$ PIPES buffer overnight and then dehydrated in different ethanol dilutions. After being embedded in Technovit 7100 for 2 weeks, gall tissues were sectioned into 10- $\mu$ m slices with a Leica RM2265 (Leica Microsystems, Beijing, China). Slices on glass slides were stained with $0.05 \%$ toluidine blue and sealed with DPX mountant. Microscopic observations were performed under an Olympus SZX 16 at $40 \times$ magnification, and images were obtained with an Olympus DP74 (Olympus Optical Company, Tokyo, Japan). The experiment was repeated twice.

\section{Development of nematodes in greenhouse experiments}

To determine the direct effect of $\mathrm{a} \beta-\mathrm{DC}$ on the development of nematodes, J2s of M. graminicola were incubated in a $\beta-D C$ solution $\left(240 \mu \mathrm{g} \mathrm{mL}^{-1}\right)$ or $1 \%$ DMSO solution for $24 \mathrm{~h}$ before inoculation. Each 2week-old rice plant was inoculated with $200 \mathrm{~J} 2 \mathrm{~s}$ around the roots and maintained in the greenhouse at $28 \pm 2{ }^{\circ} \mathrm{C}$. At $14 \mathrm{dpi}$, root samples were collected, and nematodes in rice roots were counted under a stereomicroscope after staining with acid fuchsin for $3 \mathrm{~min}$ [26]. The total numbers of nematodes in the third or fourth stage $(\mathrm{J} 3 / \mathrm{J} 4)$ and females were counted. To calculate the ratio of nematodes at various stages, the numbers of nematodes in different life stages (female or J3/J4) were divided by the total numbers of nematodes in roots using Microsoft Excel 6.0 (Redmond, Washington, USA). The entire experiment was performed thrice, each containing 6 individual plants.

\section{Infectivity of nematodes in the field experiment}

The field experiment was continuously carried out in a commercial direct-seeding field in Hunan Province, China, from July to September in 2017 and 2018. Rice had been cultivated in this field for at least 40 years and was naturally infected with M. graminicola for 10 years [43]. To ensure the nematodes were evenly distributed in the field, the soil was mixed well with a rotary cultivator. To prevent the spread of nematodes, each plot $(4 \mathrm{~m} \times 5 \mathrm{~m}$ ) was constructed with an earthen levee (height of $25 \mathrm{~cm}$ and width of $30 \mathrm{~cm}$ ) as described in Khanam et al. [17]. In total, four treatments were evaluated in a randomized block design, with 4 replicates, as follows: (1) $480 \mu \mathrm{g} \mathrm{mL}^{-1} \mathrm{a \beta}$-DC (15 ml m $\mathrm{m}^{-2}$ ), (2) $48.6 \%$ fosthiazate EC (2 ml $\left.\mathrm{m}^{-2}\right)$, (3) $41.7 \%$ fluopyram SC $\left(0.15 \mathrm{ml} \mathrm{m}^{-2}\right)$, and (4) untreated control with only $2 \mathrm{~L} 1 \%$ DMSO solution. Each agent was diluted with $2 \mathrm{~L}$ DMSO solution and sprayed evenly on the nursery bed before seeding. 
Approximately $100 \mathrm{~g}$ of seeds were directly seeded on each plot after soaking in water at room temperature for $9 \mathrm{~h}$. At $50 \mathrm{~d}$ after direct seeding, 20 seedlings from each plot were uprooted and washed free of soil. Root galling was rated on a scale of 0 to 5 , where level $0=$ no galls, level $1=1 \rrbracket 2$, level $2=$ $3 \otimes 10$, level $3=11 \otimes 20$, level $4=21 \llbracket 30$, and level $5 \geq 30$ galls per root system [31]. The gall index was calculated using the formula described in Zhan et al. [43]. The control efficacy was calculated according to the following formula: control efficacy $(\%)=100 \times$ (gall index of control-gall index of treatment) /gall index of control.

\section{Statistical analysis}

The mean and standard errors (SE) of the data were subjected to statistical analysis using SAS software version 8.0 (SAS Institute, Cary, NC). Significant differences $(P \leq 0.05)$ between the treatments were determined according to Duncan's multiple range test.

\section{Declarations}

\section{Abbreviations}

aß-DC:aß-dehydrocurvularin; $\mathrm{LC}_{50}$ :median lethal concentration; RKN:root-knot nematode; PDB:potato dextrose broth; SAP:synthetic absorbent polymer; J2: second-stage juvenile; FOS: fosthiazate; FLU: fluopyram; DMSO: dimethyl sulfoxide;hpi:hour post inoculation; dpi:day post inoculation

\section{Ethics approval and consent to participate}

The authors declare that ethic problems are not applicable.

\section{Consent for publication}

Not applicable.

\section{Funding}

This work was funded by the National Natural Sciences Foundation of China (31571986) and the National Basic Research Program of China (2013CB127502).

\section{Competing interests}

The authors declare that they have no competing interests. 


\section{Availability of data and materials}

All data generated or analysed during this study are included in this published article.

\section{Acknowledgements}

Not applicable.

\section{Author's contribution}

WKH and DLP conceived the study and supervised all of the experiments. CX and YL performed most of the experiments. YFH participated in the isolation and identification of nematicidal compounds from fungus. HP, LAK and MYL participated in the nematode inoculation experiment and field experiment. SML and $\mathrm{JL}$ helped to draft the manuscript. WKH and CX discussed the results and wrote the manuscript. All authors read and approved the final manuscript.

\section{References}

1.

Ajwa HA, Trout T, Mueller J, Wilhelm S, Nelson SD, Soppe R, et al. Application of alternative fumigants through drip irrigation systems. Phytopathology. 2002;92:1349-55.

2.

Anwer M. A characterization of some isolates of Aspergillus niger and evaluation of their effects against Meloidogyne incognita. Ann Appl Biol. 2006;27:33-4.

3.

Beketov MA, Liess M. Acute and delayed effects of the neonicotinoid insecticide thiacloprid on seven freshwater arthropods. Environ Toxicol Chem. 2008;27:461-70.

4.

Caputo O, Viola F. Isolation of a, beta-dehydrocurvularin from Aspergillus aureofulgens. Planta Med. 1977;31:31-2. 
5.

Chen SY, Dickson DW. A technique for determining live second-stage juveniles of Heterodera glycines. J Nematol. 2000;32:117-21.

6.

Cheng L, Xu S, Xu C, Lu H, Zhang Z, Zhang D, et al. Effects of trans-2-hexenal on reproduction, growth and behaviour and efficacy against the pinewood nematode, Bursaphelenchus xylophilus. Pest Manag Sci. 2017;73:888-95.

7.

Diez JA, Dusenbery DB. Repellent of root-knot nematodes from exudate of host roots. J Chem Ecol. 1989;15:2445-55.

8.

Dutta T, Ganguly A, Gaur HS. Global status of rice root-knot nematode, Meloidogyne graminicola. Afr J Microbiol Res. 2012;6:6016-21.

9.

G

Gheysen

MG

Mitchum

2009

Gheysen G, Mitchum MG. Molecular insights in the susceptible plant response to nematode infection. In: Berg RH, Taylor CG, editors. Cell Biology of Plant Nematode Parasitism. Berlin Heidelberg:Springer; 2009, p. $45-81$.

10.

Hu Y, Zhang W, Zhang P, Ruan W, Zhu X. Nematicidal activity of chaetoglobosin A poduced by Chaetomium globosum NK102 against Meloidogyne incognita. J Agric Food Chem. 2013;61:41-6. 11.

Jang JY, Choi YH, Shin TS, Kim TH, Shin KS, Park HW, et al. Biological control of Meloidogyne incognita by Aspergillus niger F22 producing oxalic acid. PLoS One. 2016;11:e0156230.

12.

Ji H, Gheysen G, Denil S, Lindsey K, Topping JF, Nahar K, et al. Transcriptional analysis through RNA sequencing of giant cells induced by Meloidogyne graminicola in rice roots. J Exp Bot. 2013;64:3885-98. 13.

Jin N, Liu SM, Peng H, Huang WK, Kong LA, Wu YH, et al. Isolation and characterization of Aspergillus niger NBC001 underlying suppression against Heterodera glycines. Sci Rep. 2019;9:591.

14.

Kearn J, Ludlow E, Dillon J, O'Connor V, Holden-Dye L. Fluensulfone is a nematicide with a mode of action distinct from anticholinesterases and macrocyclic lactones. Pestic Biochem Physiol. 2014;109:44-57. 15.

Khan MR, Zaidi B, Haque Z. Nematicides control rice root-knot, caused by Meloidogyne graminicola. Phytopathol Mediterr. 2012;51:298-306. 
16.

Khan Z, Kim SG, Jeon YH, Khan HU, Son SH, Kim YH. A plant growth promoting rhizobacterium, Paenibacillus polymyxa strain GBR-1, suppresses root-knot nematode. Bioresour Technol. 2008;99:301623.

17.

Khanam S, Akanda AM, Ali MA, Kyndt T, Gheysen G. Identification of Bangladeshi rice varieties resistant to ufra disease caused by the nematode Ditylenchus angustus. Crop Prot. 2016;79:162-9.

18.

Kusano M, Nakagami K, Fujioka S, Kawano T, Shimada A, Kimura Y. ßy-dehydrocurvularin and related compounds as nematicides of Pratylenchus penetrans from the fungus Aspergillus sp. Biosci Biotechnol Biochem. 2003;67:1413-6.

19.

Kyndt T, Fernandez D, Gheysen G. Plant-parasitic nematode infections in rice: molecular and cellular insights. Annu Rev Phytopathol. 2014;52:135-53.

20.

Kyndt T, Vieira P, Gheysen G, De Almeida-Engler J. Nematode feeding sites: unique organs in plant roots. Planta. 2013;238:807-18.

21.

Le HTT, Padgham JL, Sikora RA. Biological control of the rice root-knot nematode Meloidogyne graminicola on rice, using endophytic and rhizosphere fungi. Int J Pest Manag. 2009;55:31-6. 22.

Le HTT, Padgham JL, Hagemann MH, Sikora RA, Schouten A. Developmental and behavioural effects of the endophytic Fusarium moniliforme Fe14 towards Meloidogyne graminicola in rice. Ann Appl Biol. 2016;169:134-43.

23.

Li S, Duan YX, Zhua XF, Chen LJ, Wang YY, Pan LL. Effects of adding secondary metabolites of Aspergillus niger on resistance to tomato root-knot nematode. China Veg. 2011;4:44-9.

24.

Liu Y, Ding Z, Peng DL, Liu SM, Kong LA, Peng H, et al. Evaluation of the biocontrol potential of Aspergillus welwitschiae against the root-knot nematode Meloidogyne graminicola in rice (Oryza sativa L.). J Integr Agric. 2019;18:1-10.

25.

Menjivar RD, Hagemann MH, Kranz J, Cabrera JA, Dababat AA, Sikora RA. Biological control of Meloidogyne incognita on Cucurbitaceous crops by the non-pathogenic endophytic fungus Fusarium oxysporum strain 162. Int J Pest Manag. 2011;57:249-53.

26.

Nahar K, Kyndt T, De Vleesschauwer D, Hofte M, Gheysen G. The jasmonate pathway is a key player in systemically induced defense against root knot nematodes in rice. Plant Physiol. 2011;157:305-16. 27. 
Nusbaum CJ, Barker KR. A rapid flotation-sieving technique for extracting nematodes from soil. Plant Dis Rep. 1966;50:954-7.

28.

Oostendorp M, Sikora R. In vitro interrelationships between rhizosphere bacteria and Heterodera schachtii. Rev Nematol. 1990;13:269-74.

29.

Padgham JL, Duxbury JM, Mazid AM, Abawi GS, Hossain M. Yield loss caused by Meloidogyne graminicola on lowland rainfed rice in Bangladesh. J Nematol. 2004;36:42-8.

30.

Padilla PA, Ladage ML. Suspended animation, diapause and quiescence: arresting the cell cycle in C. elegans. Cell Cycle. 2012;11(9):1672-9.

31.

Pederson GA, Windham GL. Resistance to Meloidogyne incognita in trifolium interspecific hybrids and species related to white clover. Plant Dis. 1989;73:567-9.

32.

Prasad JS, Somasekhar N, Varaprasad KS. Nematode infestation in paddy, in Nematode Infestations. In: Khan MR, Jairajpuri MS, editors. Food Crop. India: NASI; 2010. pp. 17-71.

33.

Prasad SK, Rao YS. Drench pesticide treatment to control the root knot nematode Meloidogyne graminicola. Int Rice Res Notes. 1977;2:20.

34.

Robeson D, Strobel G. aß-dehydrocurvularin and curvularin from Alternaria cinerariae. Z Naturforsch. 1981;36:1081-3.

35.

Ruanpanun P, Laatsch H, Tangchitsomkid N, Lumyong S. Nematicidal activity of fervenulin isolated from a nematicidal actinomycete, Streptomyces sp. CMU-MH021, on Meloidogyne incognita. World J Microbiol Biotechnol. 2011;27:1373-80.

36.

Saikia SK, Tiwari S, Pandey R. Rhizospheric biological weapons for growth enhancement and Meloidogyne incognita management in Withania somnifera cv. Poshita Biol Control. 2013;65:225-34. 37.

Siddiqui IA, Shaukat SS, Khan A. Differential impact of some Aspergillus species on Meloidogyne javanica biocontrol by Pseudomonas fluorescens strain CHA0. Lett Appl Microbiol. 2004;39:74-83. 38.

Soriano IR, Reversat G. Management of Meloidogyne graminicola and yield of upland rice in SouthLuzon, Philippines. Nematology. 2003;5:879-84.

39.

Tsai WT. Environmental and health risks of sulfuryl fluoride, a fumigant replacement for methyl bromide. J Environ Sci Health C Environ Carcinog Ecotoxicol Rev. 2010;28:125-45.

40. 
Vu T, Hauschild R, Sikora R. Fusarium oxysporum endophytes induced systemic resistance against Radopholus similis on banana. Nematology. 2006;8:847-52.

41.

Wang C, Lower S, Williamson V. Application of pluronic gel to the study of root-knot behaviour. Nematology. 2009;11:453-64.

42.

Wang C, Ulloa M, Mullens TR, Yu JZ, Roberts PA. QTL analysis for transgressive resistance to root-knot nematode in interspecific cotton (Gossypium spp.) progeny derived from susceptible parents. PLoS One. 2012;7:e34874.

43.

Zhan LP, Peng DL, Wang XL, Kong LA, Peng H, Liu SM, et al. Priming effect of root-applied silicon on the enhancement of induced resistance to the root-knot nematode Meloidogyne graminicola in rice. BMC Plant Biol. 2018;18:50.

\section{Figures}

\section{Figure 1}

Chemical structure of aß-dehydrocurvularin isolated from Aspergillus welwitschiae AW2017.

\section{Figure 2}

Concentration-mortality curves of Meloidogyne graminicola exposed to $a \beta-D C$, fosthiazate or fluopyram for $48 \mathrm{~h}$. Values are the mean $\pm \mathrm{SE}$ of six replicates from three trials.

\section{Figure 3}

Attraction of M. graminicola towards the rice root tip after drenching with a $\beta$-DC or DMSO solution. (A). Nematodes attracted to within $5 \mathrm{~mm}$ around the root tip were counted at 6 hpi. (B). Nematodes around the root tip were photographed under a Leica stereomicroscope with a DFC400 camera. The entire experiment was performed thrice, with four replicates. 
A

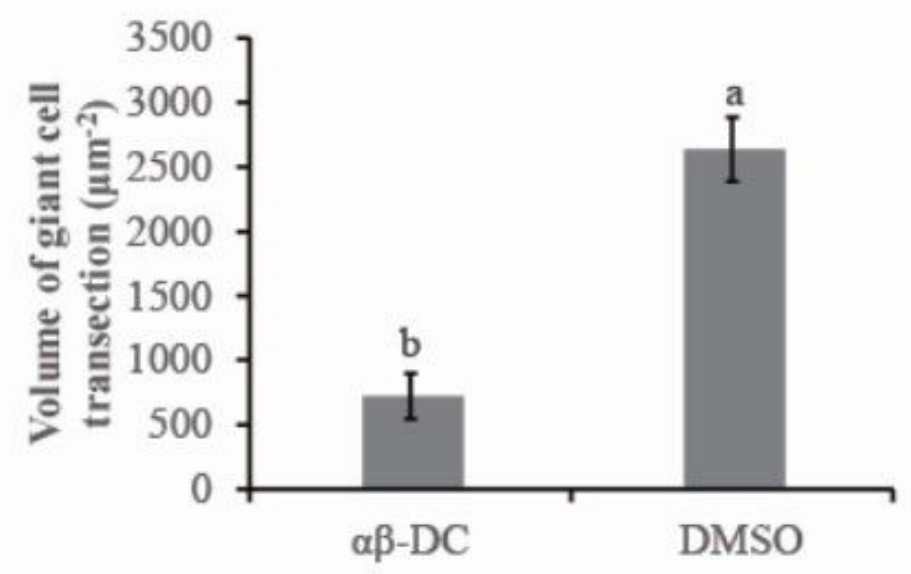

B
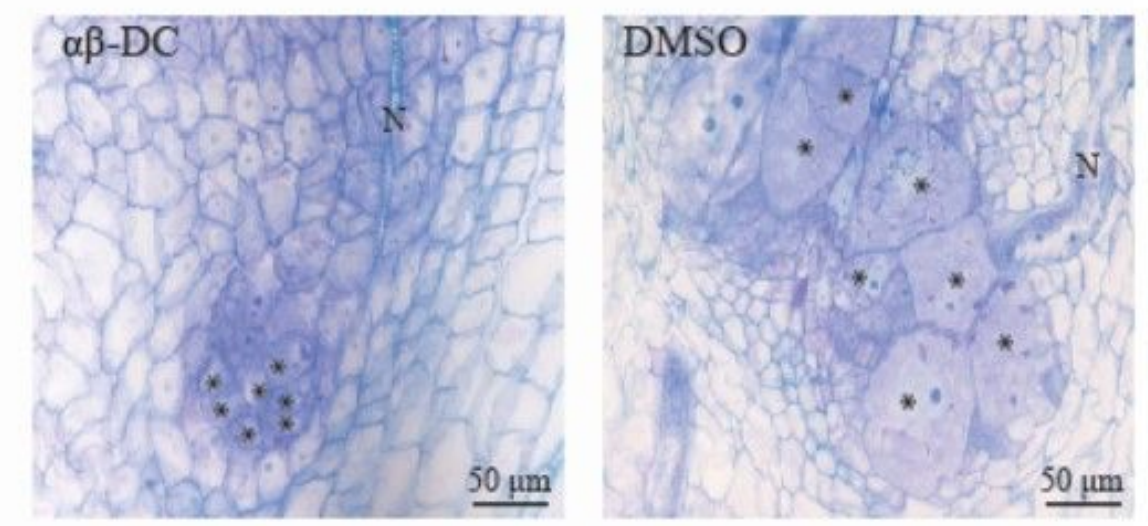

C

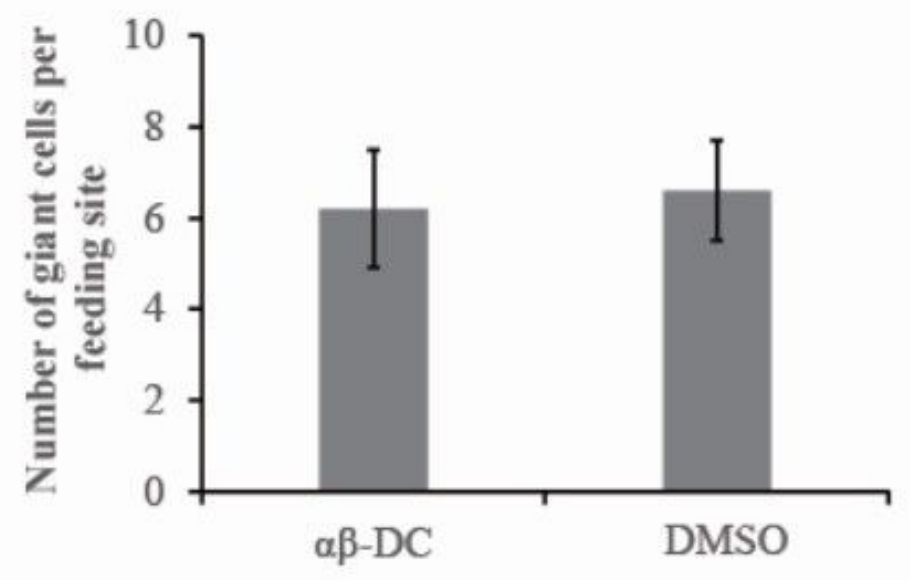

\section{Figure 4}

Analysis of giant cell structures in rice root galls after treatment with aß-DC or DMSO solution. (A) Volume of each giant cell transection. (B). Giant cells $\left.{ }^{*}\right)$ induced by the nematode $(N)$ in a $\mathrm{B}$-DC-amended root galls and DMSO solution were stained at $7 \mathrm{dpi}$ with toluidine blue solution and photographed under an Olympus DP74 (bar=50 $\mu \mathrm{m}$ ). N denotes the nematode. (C). Numbers of giant cells at each feeding site. The experiment was repeated twice, with ten galls in each treatment. 
A

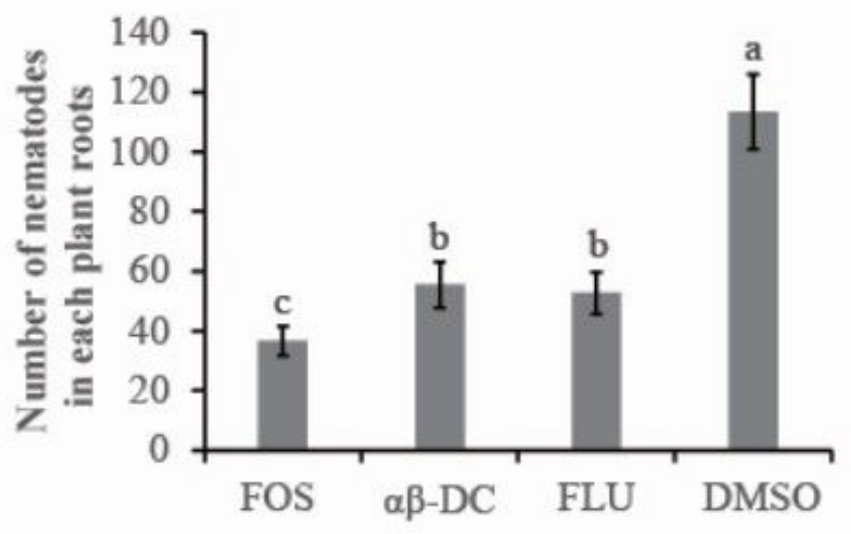

B

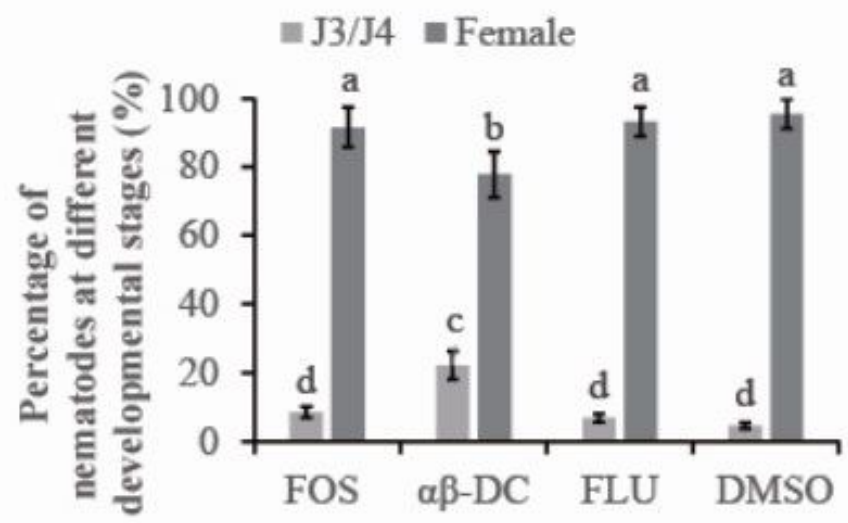

C
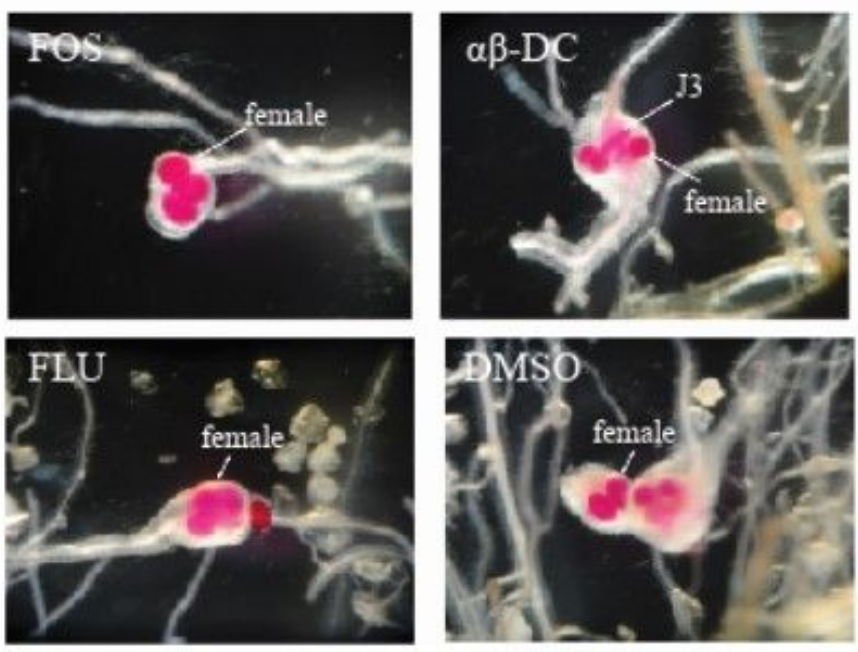

\section{Figure 5}

Effect of $a \beta-D C$ amendment on nematode infection and development under greenhouse conditions. (A). Nematodes in each aß-DC, fosthiazate or fluopyram-amended root system were counted at $14 \mathrm{dpi}$. Drenching with DMSO solution was used as a control. (B). The ratio of nematodes in rice roots at different developmental stages is the value of the numbers of nematodes in different life stages (female or $\mathrm{J} 3 / \mathrm{J} 4$ ) divided by the total numbers of nematodes in roots. (C). Nematodes in root galls were stained 
with acid fuchsin and photographed under a Leica stereomicroscope with a DFC400 camera. The bars in the different graphs represent the mean $\pm S E$ of data from three independent biological replicates, each containing 6 individual plants. Different letters indicate statistically significant differences (Duncan's multiple range test at $P \leq 0.05)$.

A

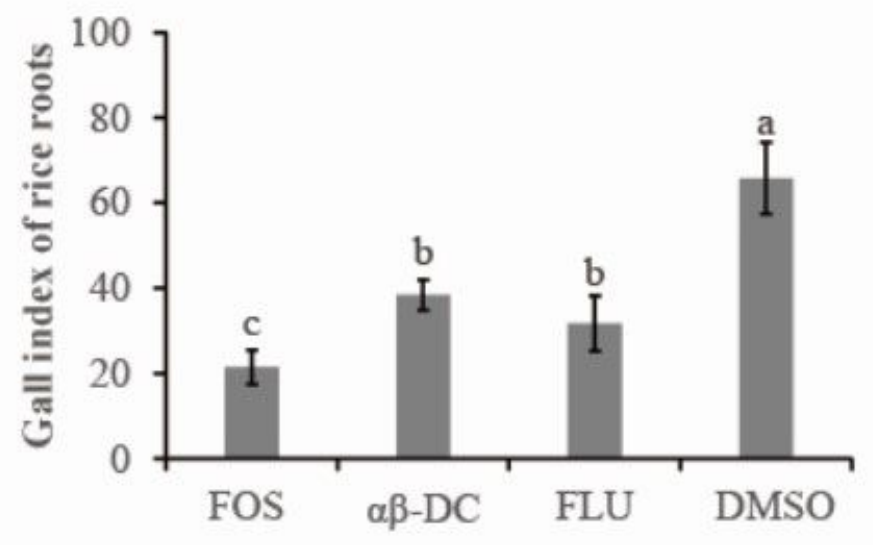

B

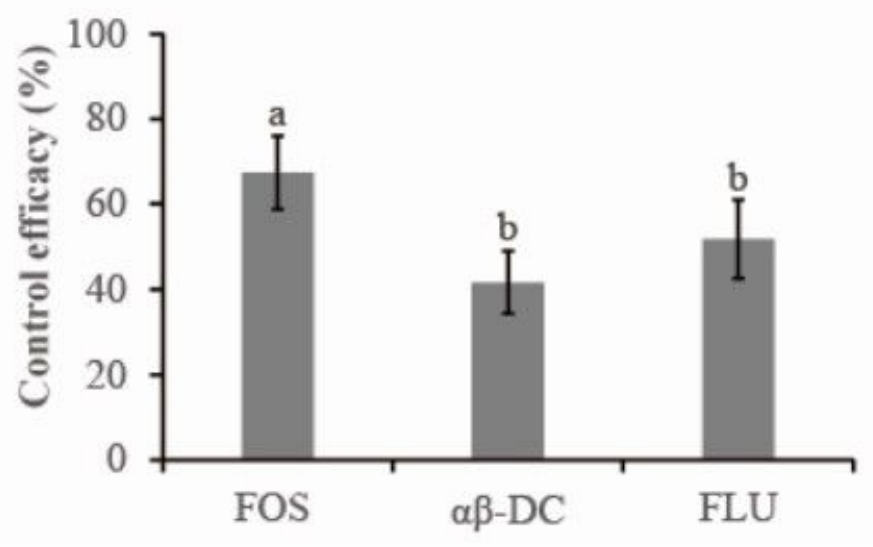

Figure 6

Effect of $a \beta-D C$ amendment on nematode infection under field conditions. (A). Root gall index in $a \beta-D C$, fosthiazate or fluopyram-amended root systems was statistically analysed at $50 \mathrm{~d}$ after direct seeding. Twenty seedlings from each plot were uprooted and analysed. (B).The control efficacy in different treatments. Treatments in both 2017 and 2018 were evaluated in a randomized block design with 4 replicates. Different letters indicate statistically significant differences (Duncan's multiple range test at $P$ $\leq 0.05)$. 